Horton's book. Without firm evidence of measles infection or of the measles virus in the MMR vaccine being involved in disease, why was the claim of an association between autism, the measles virus and the MMR vaccine placed in the results section of the paper? In Horton's defence, the same issue of The Lancet published a commentary pointing out the defects in Wakefield's paper, but the question remains: why did The Lancet open Pandora's box?

Good science demands objectivity based on experimental or clinical evidence that is reliable and reproducible. Subjective opinion is not proof and has no place in the peer-reviewed literature. Indeed, as quoted in Horton's book, Britain's chief medical officer, Liam Donaldson, stated: "If the paper had never been published, then we wouldn't have had the controversy, we wouldn't have had the seed of doubt sown in parents' minds which has caused a completely false loss of confidence in a vaccine that has saved millions of children's lives around the world." Donaldson is correct.

What's more, the continued focus of Wakefield, journalists and parents of autistic children on autism's link with measles, coupled with the complacency of a public that has been shielded from the horrors of uncontrolled infections, has supported a continued antivaccination movement. This has had a regrettable influence on the public and the political establishment concerning measles and autism specifically, and vaccination in general.

Michael B. A. Oldstone is head of the Division of Virology, Department of Neuropharmacology,

The Scripps Research Institute, 10550 North Torrey Pines Road, La Jolla, California 92037, USA.

\section{Across the border}

\author{
Alien Species and Evolution: The \\ Evolutionary Ecology of Exotic \\ Plants, Animals, Microbes, and \\ Interacting Native Species \\ by George W. Cox \\ Island Press: 2004.377 pp. $\$ 75$ (hbk), \\ $\$ 40$ (pbk)
}

\section{David M. Lodge}

While some governments are preoccupied with preventing border crossings by terrorists, thousands of alien species (those from other regions or continents) continue to be allowed free entry into most countries of the world. Some of these alien species are certain to cause great harm to the environment, native species, national economies and human health, as other species have done in the past. In this era of supposedly great attention to border security, how do the aliens keep on getting through?

Commercial markets in live food, pets,

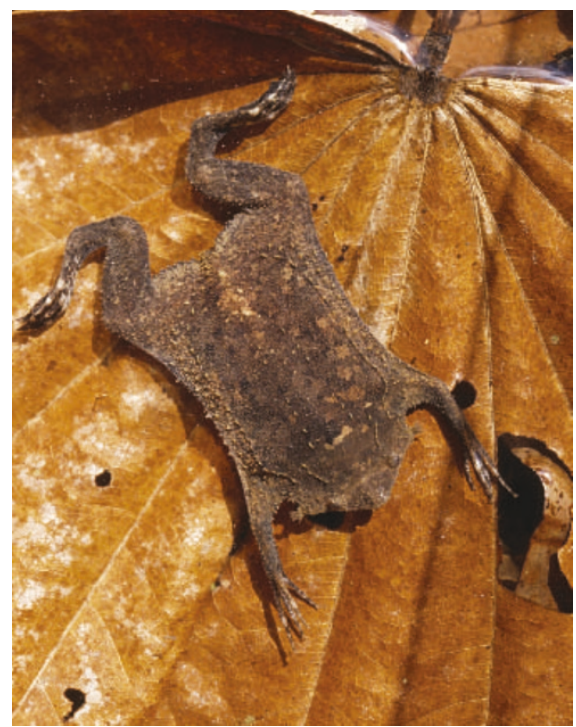

Alien invader: the Surinam toad was introduced to Australia from its native South America.

horticulture and aquaculture intentionally import a wide range of alien species into many countries every year, with little government supervision and often no analysis of the attendant environmental, health and financial risks. Thousands of other species hitch-hike on legitimate cargo or the ships, planes and other vehicles that carry them.

Most of these aliens will do little or no harm, but some will cause irreversible damage. Recent examples include the North American grey squirrel in Europe; the Asian longhorned beetle in North America; the Northern Pacific seastar and the Surinam toad in Australia; the European red deer in South America; the South American water hyacinth in Africa; and the Australian brown tree snake on Pacific islands. Changing patterns of trade mean that increasing numbers of alien species come from previously isolated regions.

The environmental and economic damage wrought by alien species includes the extinction of native species, and large alterations in ecosystem characteristics, such as nutrient fluxes and fire frequency. Charles Elton anticipated many of these environmental effects in his 1958 book The Ecology of Invasions by Animals and Plants. Indeed, it often seems that invasion biology (a recent addition to the list of biological subspecialisms) is little more than Elton redux. However, in Alien Species and Evolution, George Cox extends traditional concerns about alien species beyond the ecological theatre, and puts the evolutionary play on centre stage. His main concern is genetic change, both in alien species, which are subject to founder effects and new selection pressures, and in native species, as they experience new selection pressures imposed by the aliens.

This extremely readable book is aimed primarily at students and researchers. Cox provides comprehensive coverage of alien species in different taxonomic groups and in different habitats: terrestrial, freshwater and marine. Replete with examples and abundantly referenced, the book provides an excellent evolutionary synthesis. Cox occasionally makes extended forays beyond alien species, but only to illustrate the broader context in which adaptation and counteradaptation occur. The book is therefore also a good introduction to the broader intellectual landscape of evolution and global environmental change.

The coverage of hybridization between alien and native species may be particularly useful, as many readers might not have encountered it before. The interaction between hybridization and polyploidy has already produced a number of new terrestrial plant species from ancestral species, for instance when European salsifies (Tragopogon) were introduced into North America. Hybridization and introgression have also been common in freshwater fishes, crustaceans and molluscs, as human interventions have brought closely related species together. This often results in the loss of native species as an evolutionary and ecological entity, as well as a chance to study evolution in action.

Cox provides a guide to other research topics where an understanding of evolution is essential, including the development of invasion resistance by native communities. He considers evolution during lag times of invasion, which arise because different lifehistory characteristics are often required for dispersal and persistence in a particular environment. Cox also provides an introduction to coevolution between alien and native species, and to the effect of invasion on geographic speciation - although he makes it clear that this result is relatively minor compared with extinctions caused by invasions.

Little explicit attention is given to policy responses to species introductions, but Cox illustrates the need for greater consideration of evolutionary processes in risk analyses for alien species. In particular, he gives several examples of hybridization between wild species and related crops that have been genetically engineered for resistance to herbicides or insect pests. Transgenes have already flowed (or almost certainly will if they haven't already) from cultivated sorghum into Johnson grass, from oilseed rape into field mustard, from sunflower crops into wild sunflowers, and from wheat into jointed goatgrass. Wild species do not seem to suffer any reduction in fitness from incorporating some transgenes, contrary to the claims of many proponents of genetic engineering, so there are likely to be detrimental effects on native insects. Cox convincingly makes the case that evolution is central to any understanding of invasions, and that the analysis of risk is incomplete 
without a consideration of evolution. David M. Lodge is at the National Center for Ecological Analysis and Synthesis, Santa Barbara, California 93101, USA. He is on sabbatical from the University of Notre Dame, Notre Dame, Indiana 46556, USA.

Exhibition

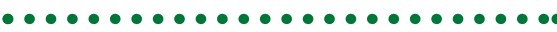
And all was light

The Newtonian Moment: Science and the Making of Modern Culture Curated by Mordechai Feingold

At The New York Public Library until 5 February 2005.

\section{Alan Packer}

Isaac Newton is rarely out of the news these days. Last year there was the publication

of Isaac Newton, James Gleick's elegant distillation of Newton's character and science. Last month came the final instalment of The Baroque Cycle, Neal Stephenson's rollicking trilogy of novels, in which Newton plays a pivotal role. Now he gets the scholarly treatment in The Newtonian Moment: Science and the Making of Modern Culture, an exhibition at The New York Public Library.

Curated by Mordechai Feingold of the California Institute of Technology, the exhibit presents maps, prints, books and models from the

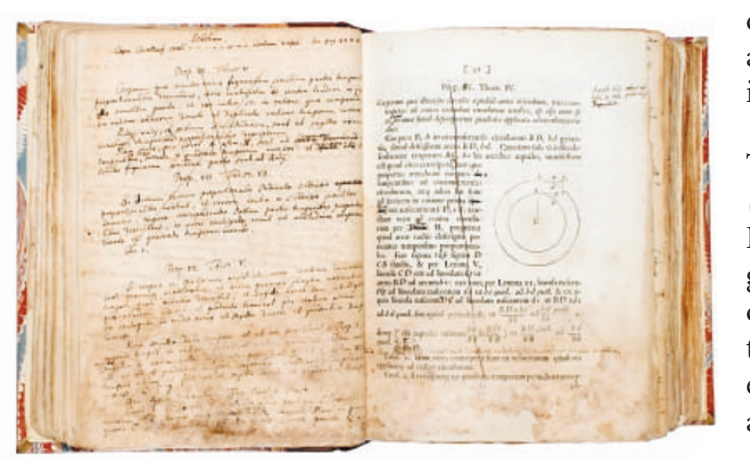

Page proofs? A first edition of Principia Mathematica with Newton's handwritten notes on the left page. library's collection, and manuscripts from the Cambridge University library. Newton's death mask, once owned by Thomas Jefferson, is also on display. The narrative focuses on Newton as "innovator and icon of the Enlightenment", and traces the reception of his ideas in their historical context.

Who would not be moved by the sight of one of Newton's early notebooks, remarkably well preserved, or an early edition of the Principia Mathematica (1687) with handwritten notes for proposed revisions? Bibliophiles will enjoy the different editions of the Principia, and Opticks (1704), translated into a variety of languages. Some of these are adorned with a dramatic allegorical frontispiece celebrating Newton's mastery of celestial and terrestrial mechanics and his revelatory insights into light and colour.

But if the exhibition emphasizes the apotheosis of Newton, it makes clear that his was not an easy road to glory. For every Voltaire - whose Elements of Newton's Philosophy was one of the most successful popularizations of newtonian thought - there was a Celestino Cominale (Anti-Newtonianismpars prima), or an Etienne Simon de Gamaches, who held fast to his compatriot Descartes' theory of vortices in the face of Newton's theory of universal gravitation. And there

was a long-running dispute between Newton and Leibniz over which of them deserved the credit for discovering the calculus.

Feingold also presents the texts and drawings of important figures whose work and world-views were affected by Newton: William Blake and his illustrations of reason and imagination; Alexander Pope ("God said Let Newton be! and All was Light”); as well as Immanuel Kant, Johann Wolfgang von Goethe and Denis Diderot. All of these were forced to confront the revolution in mathematical rigour that Newton had launched.

Newton's passion for mathematics also fuelled his idiosyncrasies. Accompanying his diagrams is a floor-plan of Solomon's Temple, whose dimensions he painstakingly derived from biblical descriptions. Newton kept this obsession, among others, carefully concealed during his lifetime.

Alan Packer is senior editor at Nature Genetics.

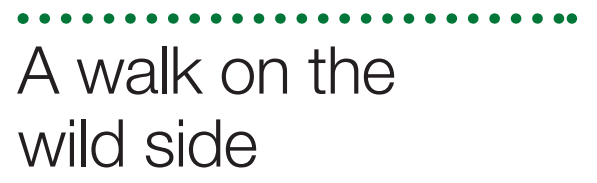

Out of this World: Colliding Universes, Branes, Strings, and Other Wild Ideas of Modern Physics by Stephen Webb

Copernicus: 2004.308 pp. $€ 29.95, £ 17.50$, $\$ 27.50$

\section{Frank Close}

"This book is about some really wild ideas," is how Out of This World begins, so readers cannot say they have not been warned. I lost count of the number of times that 'wild' was juxtaposed with 'ideas', although other adjectives, including 'outrageous', 'phenomenal' and 'outlandish' are also used to describe the "amazing recent theories" on hidden dimensions, branes and modern particle physics.

The book is about high-energy physics; if readers have enough energy of their own, they might pick up some of the sense of excitement in the current research, but they shouldn't expect suddenly to see the light. I remember seminars where the speaker attempts to review the field in the first three minutes to set the stage for the presentation; those who know the field don't need it, and those who don't aren't likely to learn much. Too often I was left with this feeling as I ploughed through this book: we are given brief glimpses of the standard model, grand unification theories and supersymmetry, superstrings and more.

Stephen Webb tries to describe the panoply of particle physics without using equations, which is a noble aim. He must have read widely to achieve this, although on occasion his sources can be rather visible; an allusion to the strength of the weak force being like Cleopatra falling off her barge in $50 \mathrm{BC}$ but not yet hitting the water rang a bell, for example. The book falls short of existing books, such as Brian Greene's The Elegant Universe (W.W. Norton, 1999), which covers much of the material with greater assurance. There is too much in Webb's book that raises doubts about the reliability of the material and suggests that Out of This World is out of its depth.

Here is a sample, by no means exhaustive. The book states that a particle with "zero rest (sic) mass" always travels at the speed of light. Poorly drawn or incorrectly labelled diagrams violate electric charge, illegally convert quarks into leptons, or show the strength of the weak force, an SU(2) structure, strengthening at energies above $100 \mathrm{GeV}$, whereas it actually starts to become feeble again.

There is the wild idea that "on average, two quarks in a free neutron come close enough to exchange a $\mathrm{W}$ boson about once every ten minutes". If the author is equating the ten-minute half-life of the neutron with the chance that the $\mathrm{W}$ boson can initiate the "weak" beta decay, this is misleading. The typical lifetime of a particle resisting beta decay is of the order of nanoseconds or less: the longer lifetime of the neutron is mainly due to the fact that the combined masses of proton and electron, into which the neutron decays, are so close to that of the free neutron that there is almost no 'phase space' available.

To popularize using metaphor requires the author to have a deep understanding of the material. To do this over some 300 pages without using equations is a challenge of the highest order, so it is perhaps not surprising that Webb does not always succeed. Readers might have found it easier to persevere if he had shown less ambition, following the maxim that 'less is more'. The book does provide a sense of the development of ideas, and how the frontiers of current mathematical particle physics are developing, but the descriptions are patchy and the "wild ideas" rather overstated. Without a sense of irony, the dust-jacket puff reads: "Then, in a series of increasingly astonishing chapters...”. Astonishing indeed!

Frank Close is at the Rudolf Peierls Centre for

Theoretical Physics, 1 Keble Road, Oxford

University, Oxford OX1 3NP, UK. 
a recognition of intellectual contribution, equitable distribution of benefits, capacity building and so forth - are not generally considered in this book.

This ethnoflora is set in the purely descriptive and colonial ethnobotanical traditions dating back to Linnaeus and before. Nonetheless, it is most useful for documentation, conservation and development, even if it does not advance the modern science of ethnobotany or reconcile inequities between scientific and traditional knowledge.

Jan Salick is curator of ethnobotany, Missouri

Botanical Garden, Box 299, St Louis,

Missouri 63166-0299, USA.

\section{Reforming research}

\section{Scrutinising Science: The Changing UK Government of Science \\ by Rebecca Boden, Deborah Cox, \\ Maria Nedeva \& Katherine Barker \\ Palgrave: 2004. 218 pp. $£ 45$}

\section{Brian Heap}

The dramatic changes in UK government research establishments (GREs) during the past 20 years constitute one of the most radical experiments in the organization and management of scientific research. And while these changes have been going on, mad-cow disease, foot-and-mouth disease and anthrax have thrust these labs into the public view. At other times, however, their work is less conspicuous but nonetheless highly significant for the public good.

During the 1980s and 1990s, successive Conservative governments seized the opportunity to address the perceived shortcomings of GRE laboratories. The experiment is outlined in the book Scrutinising Science, where it is seen through the lens of social and political science. The authors' analysis is based on interactions with policy-makers, senior managers and administrators tasked with carrying out their paymasters' orders, rather than on the firsthand experience of bench scientists. Some scientists found that the trauma of uncertainty and indecision resulted in planning blight and a loss of morale that was not readily reversed.

The authors helpfully trace the historical origins of the reform of GREs to theories that viewed science as a social institution: governments and politicians were supposed to fund science generously but should not intervene in the affairs of science, nor expect any tangible returns. The research councils that were formed early in the twentieth century existed on the principle of 'research council autonomy' espoused by R. B. Haldane, and other research establishments were created to serve their government departments or ministries directly. In the second half of the twentieth century,

\section{Secret sex}

Invisible to the naked eye, pollen grains are tough enough to have survived for millennia and display a wide diversity of forms, fascinating artists and scientists alike. In Pollen: The Hidden Sexuality of Flowers (Papadakis, £35), botanist Madeline Harley and artist Rob Kesseler bring pollen into closer view. The informative text is accompanied by stunning original micrographs of pollen grains, and photographs of the flowers that shed them. The book also includes engravings by previous observers of pollen, including Franz Bauer and Ernst Haeckel.

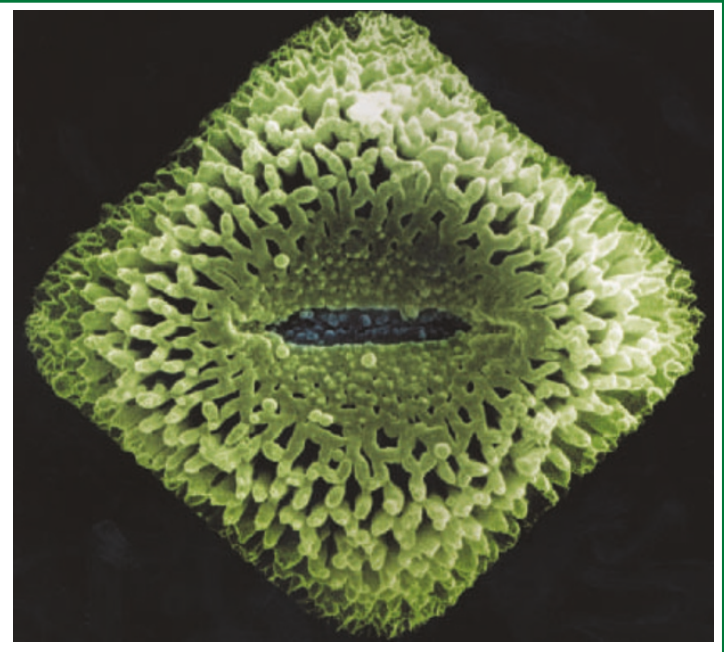

new models of governance and ownership structures appeared, or were imposed upon GREs. These models ensured closer control by departments through measures such as contractor-customer arrangements - part and parcel of making science and technology 'useful' to the departmental customer.

Later, an emerging 'new public management' (NPM) ideology pervaded government policies, driven by the practice of management by accounting. The NPM reform was driven with "breathless urgency" by politicians such as Michael Heseltine, with an outcome typified by complexity and heterogeneity. Eighteen science and technology establishments were transformed into 'next step agencies' between 1989 and 1996, with funding allocated by the contractorcustomer mechanisms; 15 establishments were translated into 'executive agencies' by 1992. The process was suspended in 1997 by the incoming Labour government. The authors conclude that the application of NPM reform to GREs was complicated, messy and driven by opportunism, because GREs were a relatively minor part of government.

What of the present? This complicated picture is addressed by a brief description of individual GREs and their current status. There is also a discussion of eight laboratories that have undergone this transformational organization, including the National Engineering Laboratory, the Laboratory of the Government Chemist, the National Physical Laboratory, the Met Office and the Defence Evaluation and Research Agency. The authors acknowledge that resistance to reform proved problematic in some sectors (the old Ministry of Agriculture, Fisheries and Food "proved itself remarkably adept at avoiding the privatisation issue"), but they discover a sense of relief in some laboratories that found themselves free of the restrictive practices of the past.

The authors are much less sanguine, however, about the long-term impact of reform, in terms of the quality of science, the way that technologies are provided to government, and in particular the transparency of reporting mechanisms and accountability to departments. Accountability to departments is now done in private, based on unpublished contracts - hardly a mechanism to instil confidence in laboratories whose functions are supposed to be transparent and carried out in the national interest.

Turning to the future, the authors express concerns resulting from the earlier policies of an "energetically reforming government" that "decided it could change things everything in fact, including science". The dissolution of GREs that had evolved over a long period of time in response to the government's need for science and technology, the creation of organizations more by accident than design, and the cost to the Exchequer of reforming GREs that were deemed eminently non-marketable - these are topics that the jury will debate for some time.

It would have been informative to evaluate in greater depth the parallel impact of NPM reform on research-council institutions, and the spillover effect in universities, too often portrayed here as remaining, in the words of economist Robert Merton, "a publicgood activity compared to a commercial one". However, this is an important and well researched book, and we should be grateful that it has been written, not least because any government bent on further reform, if it is to bring about beneficial change, would benefit from reading this recent history of the governance of science.

Brian Heap is an honorary fellow, St Edmund's College, University of Cambridge,

Cambridge CB3 OBN, UK.

\section{Erratum}

The Surinam toad that appeared alongside the recent review by David Lodge of George W. Cox's book Alien Species and Evolution (Nature 432, 276-277; 2004) was of the wrong species. The pictured toad (Pipa pipa) resides happily in South America and is not the pest (Bufo marinus) that has been introduced into Australia. Nature apologises for this mistake. 